\title{
Bactérias diazotróficas associadas a coqueiros na região de baixada litorânea em Sergipe ${ }^{(1)}$
}

\author{
Marcelo Ferreira Fernandes ${ }^{(2)}$, Roberta Pereira Miranda Fernandes ${ }^{(3)}$ e Luciana da Silva Rodrigues ${ }^{(4)}$
}

Resumo - Objetivou-se neste trabalho, isolar, identificar e quantificar bactérias diazotróficas existentes nas raízes e folhas de coqueiro (híbrido PB121) cultivados na baixada litorânea de Sergipe. As populações de bactérias diazotróficas nesses órgãos foram quantificadas pela técnica do número mais provável (NMP) em meios semi-sólidos JNFb e NFb, e identificadas por meio de avaliações microscópicas, culturais e de testes bioquímicos dos sistemas API 20-E e API 20-NE. O conteúdo de N em meios semi-sólidos NFb e JNFb foi determinado colorimetricamente, após oito dias de incubação das bactérias, a $32^{\circ} \mathrm{C}$, para estimar a capacidade de fixação biológica dos isolados. Enterobactérias pertencentes ao gênero Enterobacter e bactérias com características semelhantes às do gênero Pseudomonas (pseudomonadas) foram predominantes entre os isolados obtidos. As enterobactérias e pseudomonadas isoladas de folhas foram predominantemente endofíticas. Quanto às diazotróficas isoladas de raízes, observou-se predominância de enterobactérias na sua superfície, ao passo que as pseudomonadas ocorreram em proporções semelhantes na superfície e no interior desse órgão. Após oito dias de incubação, os conteúdos de $\mathrm{N}$ nos meios com inoculação das bactérias pseudomonadas foram maiores do que nos meios com inoculação das enterobactérias

Termos para indexação: Cocos nucifera, enterobactéria, pseudomonadas, fixação do nitrogênio.

\section{Diazotrophic bacteria associated to coconut palms in a coastal lowland region in Sergipe State, Brazil}

\begin{abstract}
The aim of this work was to isolate, identify and quantify diazotrophic bacteria existing in roots and leaves of coconut palms (hybrid PB121) grown in a coastal lowland of Sergipe, in Brazil. Diazotrophic populations in these organs were quantified by the most probable number (MNP) technique on $\mathrm{NFb}$ and $\mathrm{JFF}$ semi-solid media and identified by the evaluation of microscopic, cultural and biochemical characteristics of the isolates. Biochemical characteristics were evaluated using the API 20-E and API 20-NE galleries. Nitrogen content in NFb and JNFb semi-solid media inoculated with each of the isolates and incubated for eight days at $32^{\circ} \mathrm{C}$ was colorimetrically evaluated to estimate the biological nitrogen fixation capacity of the isolates. Bacteria of the Enterobacter genus and pseudomonads formed the predominant types of $\mathrm{N}_{2}$-fixers. Enterobacteria and pseudomonads isolated from leaves were predominantly endophytic. Regarding to the diazotroph bacteria isolated from roots, it was observed that enterobacteria were predominant in the root-surface, while pseudomonads were found in nearly equivalent proportions in the surface and in the interior of this organ. After eight days of incubation, pseudomonads isolates presented higher $\mathrm{N}$ fixation capacity than enterobacteria
\end{abstract}

Index terms: Cocos nucifera, enterobacterium, pseudomonads, nitrogen fixation.

(1) Aceito para publicação em 2 de fevereiro de 2001 .

(2)Embrapa-Centro de Pesquisa Agropecuária dos Tabuleiros Costeiros, Av. Beira Mar, 3250, CEP 49025-040 Aracajú, SE E-mail: marcelo.fernandes@orst.edu

(3) Universidade Federal de Sergipe, Dep. de Fisiologia, Campus Universitário José Aloísio de Campos, CEP 49100-000 São Cristóvão, SE. E-mail: fernanro@mailbox.orst.edu

(4) Universidade Federal Rural do Rio de Janeiro, km 47, antiga estrada Rio-São Paulo, CEP 23851-970 Seropédica, RJ. E-mail lucianarodrigues@usa.net

\section{Introdução}

O coqueiro (Cocos nucifera L.) é cultivado predominantemente em solos tropicais ácidos e com baixos teores de nutrientes. Embora a cultura responda muito bem à adição de fertilizantes, adubações químicas não são realizadas com freqüência, principalmente pelos pequenos proprietários de terra, que constituem a maioria dos cocoicultores das 
regiões tropicais (Thomas et al., 1991). Visto que a adubação é um dos fatores que elevam a relação custo/benefício das culturas exploradas, alternativas capazes de proporcionar boa produtividade agrícola, com doses menores de fertilizantes, têm grande repercussão social e econômica.

A capacidade de fixação biológica do $\mathrm{N}$ por bactérias associadas a plantas não-leguminosas tem sido freqüentemente relatada (Li \& MacRae, 1992; Balota et al., 1997; Chiarini et al., 1998).

Bactérias diazotróficas dos gêneros Beijerinckia e Azotobacter foram detectadas no solo rizosférico de coqueiros (Nair \& Subba Rao, 1977; Subba Rao, 1983) e outras pertencentes ao gênero Azospirillum foram encontradas em associação com as raízes desta planta (Subba Rao, 1983). Além dessas bactérias, outras têm sido isoladas da rizosfera e de órgãos aéreos de diferentes culturas e apresentado crescimento abundante em meio de cultura livre de $\mathrm{N}$, indicando possuírem capacidade de fixação biológica do nitrogênio. Entre estas bactérias, Enterobacteriaceae dos gêneros Klebsiella e Enterobacter, bem como outras bactérias gram-negativas, como Pseudomonas, Azospirillum, Herbaspirillum e Alcaligenes, foram observadas na rizosfera ou na parte aérea de diversas culturas (Baldani et al., 1992; Li \& MacRae, 1992; Hinton \& Bacon, 1995; Balota et al., 1999; Engelhard et al., 2000; Reis et al., 2000).

O objetivo deste estudo foi isolar, quantificar, e identificar bactérias diazotróficas em raízes e folhas de coqueiros cultivados em região de baixada litorânea de Sergipe.

\section{Material e Métodos}

Amostras de raízes e de folhas foram retiradas de oito plantas de coqueiro híbrido PB121 (Anão Amarelo da Malásia x Gigante do Oeste Africano), com cerca de 15 anos de idade, cultivadas em área de baixada litorânea de Aracaju, SE. O solo da área amostrada é classificado como Podzol e apresenta as seguintes características químicas: pH em água $(1: 2,5)=4,9$; matéria orgânica, de acordo com o método Walkley-Black (Jackson, 1958) $=15,0 \mathrm{~g} \mathrm{dm}^{-3}$, $\mathrm{P}=4 \mathrm{mg} \mathrm{dm}^{-3}$ e $\mathrm{K}=0,02 \mathrm{cmol}_{\mathrm{c}} \mathrm{dm}^{-3}$, extraídos pelo Mehlich-1, sendo os teores de $\mathrm{P}$ determinados por colorimetria e os de $\mathrm{K}$, por fotometria de chama (Embrapa, 1997); $\mathrm{Ca}^{2+}=1,00 \mathrm{cmol}_{\mathrm{c}} \mathrm{dm}^{-3}, \mathrm{Mg}^{2+}=0,46 \mathrm{cmol}_{\mathrm{c}} \mathrm{dm}^{-3} \mathrm{e}$ $\mathrm{Al}^{3+}=0,3 \mathrm{cmol}_{\mathrm{c}} \mathrm{dm}^{-3}$, extraídos com KCl $1 \mathrm{~mol} \mathrm{~L}^{-1}$ e de- terminados por titulometria (Embrapa, 1997) $\mathrm{H}+\mathrm{Al}=1,7 \mathrm{cmol}_{\mathrm{c}} \mathrm{dm}^{-3}$, extraídos por acetato de cálcio $0,5 \mathrm{~mol} \mathrm{~L}^{-1}$ e determinados por titulometria (Embrapa, 1997). Os resultados da análise granulométrica, pelo método do densímetro (Embrapa, 1997), revelaram os seguintes resultados: areia $=760 \mathrm{~g} \mathrm{~kg}^{-1}$, silte $=98 \mathrm{~g} \mathrm{~kg}^{-1} \mathrm{e}$ argi$\mathrm{la}=142 \mathrm{~g} \mathrm{~kg}^{-1}$

As raízes foram lavadas, para remoção do solo, e cortadas em fragmentos de 2 a $4 \mathrm{~cm}$, com tesoura esterilizada. Amostras de $15 \mathrm{~g}$ de raízes e de folhas foram submetidas à desinfecção superficial (Döbereiner et al., 1995), de modo a permitir que as bactérias isoladas dessas amostras fossem consideradas endofíticas. Os procedimentos de desinfecção utilizados incluíram a imersão das raízes em solução de cloramina-T $(1 \% \mathrm{p} / \mathrm{v})$ por 45 minutos, e a desinfecção superficial das folhas com algodão embebido em etanol 75\%. Para o isolamento de bactérias diazotróficas totais (superficiais + endofíticas), amostras de $15 \mathrm{~g}$ de raízes e de folhas foram processadas de acordo com os mesmos procedimentos acima citados, substituindo-se, porém, a cloramina-T e o álcool por água estéril.

As amostras de folhas e raízes, desinfectadas ou não, foram trituradas, por dois minutos, em liquidificador com $150 \mathrm{~mL}$ de solução salina $(\mathrm{NaCl}, 0,9 \% \mathrm{p} / \mathrm{v})$ estéril. Uma homogeneização adicional do material não triturado na etapa anterior foi realizada manualmente com um almofariz e um pistilo previamente autoclavados

Os extratos obtidos foram seqüencialmente diluídos de $10^{2}$ a $10^{6}$ vezes em solução estéril de $\mathrm{NaCl}(0,9 \% \mathrm{p} / \mathrm{v})$. Alíquotas de $100 \mu \mathrm{L}$ de cada diluição foram inoculadas em triplicata em frascos de $10 \mathrm{~mL}$ (diâmetro interno de $2 \mathrm{~cm}$ ) contendo $5 \mathrm{~mL}$ dos meios semi-sólidos $\mathrm{NFb}$ (Döbereiner et al., 1995) ou JNFb (Baldani et al., 1992), livres de nitrogênio.

Os frascos foram incubados por seis dias, a $32^{\circ} \mathrm{C}$. Aqueles que apresentaram uma película fina ou difusa, na superfície ou a alguns milímetros abaixo da superfície dos meios de cultura semi-sólidos, foram submetidos à análise da atividade da nitrogenase pela técnica da redução do acetileno (Watanabe et al., 1987), para confirmação da capacidade diazotrófica das culturas. Estimou-se o número mais provável (NMP) de bactérias diazotróficas por grama de raízes ou folhas (Kleeberger et al., 1983), utilizando-se a frequiência de frascos nos quais o etileno foi detectado (resultados positivos).

Colônias de bactérias diazotróficas foram isoladas em meio sólido (15 g L $\mathrm{g}^{-1}$ de ágar) $\mathrm{NFb}$ ou JNFb com $20 \mathrm{mg} \mathrm{L}^{-1}$ de extrato de levedura, a partir dos frascos que apresentaram resultados positivos na etapa de quantificação. Após uma semana de incubação a $32^{\circ} \mathrm{C}$, procedeu-se à reinoculação de meios semi-sólidos NFb e JNFb, sem N, com colônias isoladas nos meios sólidos, para confirma- 
ção da atividade diazotrófica das bactérias. As culturas formadas nestes meios semi-sólidos foram repicadas para meios idênticos e incubadas por sete dias, a $32^{\circ} \mathrm{C}$. Esta etapa foi repetida por dez vezes consecutivas. As culturas que mantiveram crescimento em meio sem $\mathrm{N}$, após dez transferências, foram reisoladas em ágar-batata (Döbereiner et al., 1995). Vinte isolados foram selecionados, avaliados quanto ao $\mathrm{N}$ fixado após incubação em meios semi-sólidos, e identificados de acordo o Manual de bacteriologia determinativa de Bergey (Holt et al., 1994). Para essa identificação utilizaram-se as seguintes características: forma e arranjo celulares em lâminas fixadas e coradas com fucsina, motilidade em lâminas de gota pendente, coloração de Gram, demanda de $\mathrm{O}_{2}$, produção de pigmento em ágar nutriente, após seis dias de incubação, atividades da citocromo oxidase e catalase. A demanda de $\mathrm{O}_{2}$ das bactérias foi determinada em tubos de ensaio contendo ágar nutriente, e as bactérias foram misturadas ao meio de cultura ainda liquefeito $\left(52^{\circ} \mathrm{C}\right)$. Após dez dias de incubação, a $32^{\circ} \mathrm{C}$, observou-se o crescimento bacteriano nos frascos. As culturas foram consideradas aeróbias ou anaeróbias facultativas caso o crescimento tenha ocorrido na superfície ou indistintamente em todo o tubo com ágar nutriente, respectivamente. Nas placas de Petri com meios sólidos LG, LGD, NFb, LGI, JNFb e LGI-P, preparados de acordo com Döbereiner et al. (1995), foram inoculadas as culturas isoladas, para verificação de similaridades entre as características das colônias formadas e as descritas para bactérias dos gêneros Azotobacter, Azomonas, Derxia, Azospirillum, Herbaspirillum e Acetobacter. As especificações do tempo e temperatura de incubação utilizadas estão descritas em Döbereiner et al (1995). O crescimento dos isolados em meios sólidos eosina-azul de metileno e McConkey também foi avaliado, após sete dias de incubação a $32^{\circ} \mathrm{C}$.

Bastonetes anaeróbios facultativos, gram-negativos, não esporulantes, desprovidos de atividade de citocromo oxidase, foram considerados enterobactérias. Bastonetes estritamente aeróbios, gram-negativos, não esporulantes, apresentando atividade de citocromo oxidase, foram considerados como bactérias relacionadas ao gênero Pseudomonas, e foram denominados pseudomonadas (Kleeberger et al., 1983). Estes isolados foram posteriormente identificados pela utilização de sistemas de galerias API 20-E (Appareils et Procédés d'Identification, bio Mérieux, La Balme les Grottes, 38390 - Montalieu Vercieu, France). A identificação dos isolados foi feita após 48 horas de incubação a $32^{\circ} \mathrm{C}$. Isolados identificados apenas como Pseudomonas sp. com a utilização do sistema
API 20-E foram inoculados em galerias API 20-NE, recomendado para estas bactérias, e incubados por 48 horas, a $32^{\circ} \mathrm{C}$, para identificação das espécies.

A capacidade de fixação de $\mathrm{N}_{2}$ dos isolados foi avaliada pela quantificação do $\mathrm{N}$ acumulado em frascos de $10 \mathrm{~mL}$ ( $2 \mathrm{~cm}$ de diâmetro interno) contendo $5 \mathrm{~mL}$ de $\mathrm{NFb}$ ou $\mathrm{JNFb}$ semi-sólidos, inoculados com os isolados, e incubados por oito dias, a $32^{\circ} \mathrm{C}$. Frascos sem inoculação, contendo $5 \mathrm{~mL}$ dos mesmos meios de cultura, foram utilizados como controle. Cada isolado de bactéria diazotrófica foi inoculado em cinco frascos com meio de cultura idêntico àquele no qual foi isolado originalmente, de modo que cada frasco constituiu uma quintuplicata para a análise de $\mathrm{N}$. O N foi quantificado por um método colorimétrico, modificado a partir de Mitchell (1972), após a digestão do conteúdo dos frascos em solução de Kjeldahl. O método foi previamente validado por meio de determinações do $\mathrm{N}$ em meios semi-sólidos contendo concentrações conhecidas e crescentes de $\mathrm{N}\left(0\right.$ a $\left.300 \mu \mathrm{g} \mathrm{mL}^{-1}\right)$ sob as formas de soro albumina bovina $(15,3 \%$ de $\mathrm{N}), \mathrm{N}$-acetil-glicosamina, prolina, metionina e $\mathrm{NH}_{4} \mathrm{Cl}$. Os coeficientes de determinação $\left(\mathrm{R}^{2}\right)$ entre as concentrações de $\mathrm{N}$ determinado pelo método proposto e as concentrações conhecidas de $\mathrm{N}$ nos meios semi-sólidos foram superiores a $0,98 \mathrm{em}$ todas as fontes de $\mathrm{N}$ utilizadas

\section{Resultados e Discussão}

Os valores do NMP de bactérias diazotróficas foram maiores em meio $\mathrm{JNFb}$ do que em $\mathrm{NFb}$, independentemente do órgão vegetal utilizado para isolamento das bactérias e do tratamento de desinfecção empregado (Tabela 1).

O número de bactérias diazotróficas presentes nas folhas e raízes de coqueiros foi elevado, e equivalente aos encontrados nas raízes de alguns genótipos de milho (Salamone et al., 1996), sorgo e Brachiaria decumbens (Baldani et al., 1992).

Culturas isoladas a partir dos tubos positivos do teste para determinar o NMP foram todas bastonetes móveis, gram-negativos e com atividade de catalase (Tabela 2). Os sete isolados obtidos em NFb apresentaram metabolismo dependente de $\mathrm{O}_{2}$ e atividade da citocromo oxidase, sendo, assim, identificados preliminarmente como pseudomonados. No entanto, dos 14 isolados obtidos em meio JNFb, 13 apresentaram metabolismo anaeróbio facultativo e ausência 


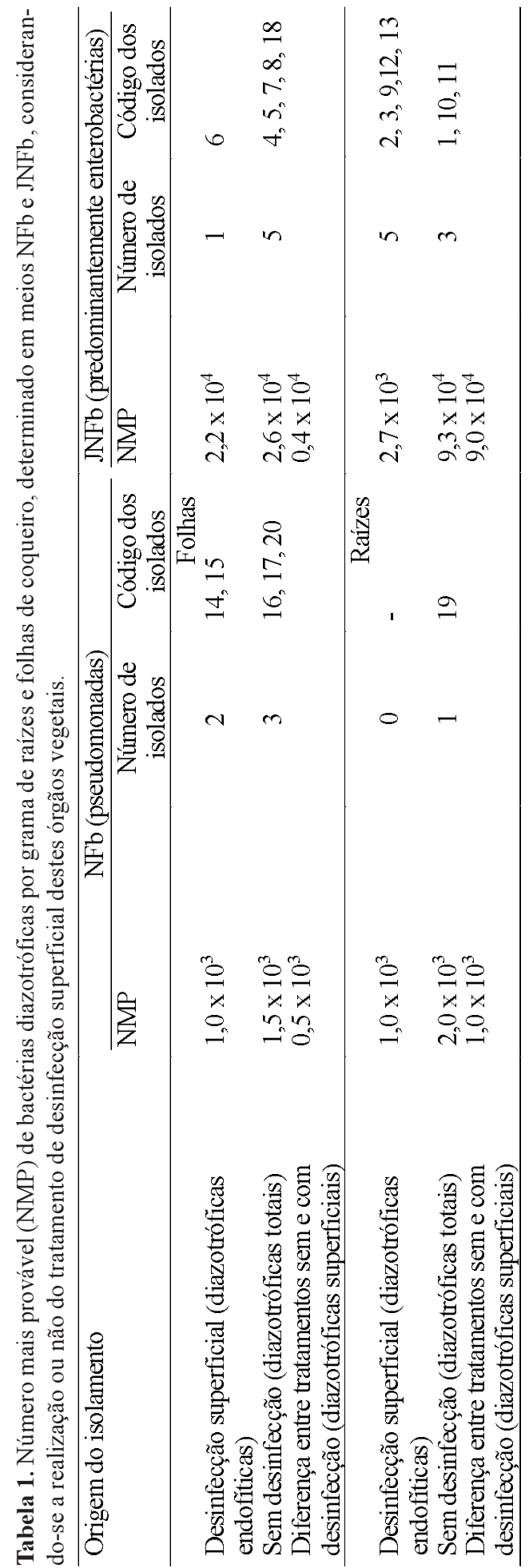

de atividade da citocromo oxidase, adequando-se à descrição de enterobactérias de Kleeberger et al. (1983). A identificação preliminar desses isolados como enterobactérias foi confirmada pelo crescimento rápido e abundante destes em meios sólidos McConkey e Eosina-Azul de Metileno (EMB) (Tabela 2).

Pelo fato de os isolados obtidos não apresentarem características culturais similares às de espécies de outras bactérias diazotróficas bem conhecidas (Azospirillum, Azotobacter, Derxia, Beijerinckia e Herbaspirillum) quando cultivadas em meios apropriados, considerou-se que as enterobactérias, seguidas das pseudomonadas, foram os grupos predominantes de diazotróficas nas folhas e raízes de coqueiro.

Quando o meio $\mathrm{JNFb}$ foi utilizado para o isolamento, a esterilização superficial reduziu marcantemente a quantidade de diazotróficos nas amostras de raízes. Entretanto, este efeito acentuado não foi observado nas amostras de folhas. Comparações dos órgãos vegetais submetidos ou não à desinfecção superficial indicaram que as enterobactérias isoladas de raízes ocorrem predominantemente na superfície das raízes, ao passo que as isoladas de folhas são mais abundantes no interior destas últimas. De acordo com os resultados dos isolamentos realizados em $\mathrm{NFb}$, as diazotróficas pseudomonadas de folhas são predominantemente endofíticas, ao passo que as de raízes foram encontradas em proporções semelhantes no interior e na superfície das raízes (Tabela 1).

De acordo com os testes bioquímicos realizados com a utilização de galerias API 20-E, todas as enterobactérias isoladas pertencem ao gênero Enterobacter (Tabela 2). Nove desses isolados foram identificados como Enterobacter cloacae, não sendo possível, no entanto, a identificação da espécie dos demais isolados de Enterobacter. Embora as características bioquímicas de todos os isolados de Enterobacter tenham sido idênticas nas galerias API 20-E, diferenças culturais foram observadas em meio EMB, já que as colônias de isolados 1 e 5 apresentam uma coloração verde-metálica não observada nas demais (Tabela 2). A espécie Enterobacter cloacae também foi relatada de ocorrer no interior de raízes de milho (Hinton \& Bacon, 1995) e na 
Tabela 2. Identificação das estirpes isoladas de folhas e raízes de coqueiro utilizando-se as características microscópicas, bioquímicas (API 20-E) e culturais em meios de cultura McConkey, EMB e ágar nutriente ${ }^{(1)}$

\begin{tabular}{|c|c|c|c|c|c|c|c|c|c|}
\hline \multirow[t]{3}{*}{ Características } & \multicolumn{9}{|c|}{ Espécies e códigos dos isolados de bactérias diazotróficas } \\
\hline & \multirow{2}{*}{$\begin{array}{c}\text { Enterobacter } \\
\text { cloacae }\end{array}$} & \multirow{2}{*}{$\begin{array}{c}\text { Enterobacter } \mathrm{sp} . \\
10 \text { a } 13\end{array}$} & \multicolumn{5}{|c|}{ Pseudomonas sp. } & \multirow{2}{*}{$\begin{array}{c}\text { Burkholderia } \\
\text { cepacia }\end{array}$} & \multirow{2}{*}{$\begin{array}{c}\begin{array}{c}\text { Sphingomonas } \\
\text { paucimobilis }\end{array} \\
19\end{array}$} \\
\hline & & & 14 & 15 & 16 & 17 & 20 & & \\
\hline Gram & - & - & - & - & - & - & - & - & - \\
\hline Mobilidade & + & + & + & + & + & + & + & + & + \\
\hline Forma & Bast. & Bast. & Bast. & Bast. & Bast. & Bast. & Bast. & Bast. & Bast. \\
\hline Orto-nitrofenil-galactosídeo & + & + & - & - & - & - & - & + & + \\
\hline Arginina dihidrolase & + & + & - & - & - & - & - & - & - \\
\hline Lisina descarboxilase & - & - & - & - & - & - & - & - & - \\
\hline Ornitina descarboxilase & - & - & - & - & - & - & - & - & - \\
\hline Utilização do citrato & + & + & - & - & + & + & + & + & - \\
\hline Produção de $\mathrm{H}_{2} \mathrm{~S}$ & - & - & - & - & - & - & - & - & - \\
\hline Urease & - & - & - & - & - & - & + & - & - \\
\hline Triptofano deaminase & - & - & - & - & - & - & - & - & - \\
\hline Produção de Indol & - & - & - & - & - & - & - & - & - \\
\hline Produção de Acetoína & + & + & + & - & - & + & + & - & + \\
\hline Hidrólise da gelatina & - & - & - & - & - & - & - & + & - \\
\hline Fermentação/oxidação de: & & & & & & & & & \\
\hline Glicose & + & + & - & $+/-$ & + & - & - & - & - \\
\hline Manitol & + & + & - & - & - & - & - & - & - \\
\hline Inositol & - & + & - & - & - & - & - & - & - \\
\hline Sorbitol & + & + & - & - & - & - & - & - & - \\
\hline Ramnose & + & + & - & - & - & - & + & - & - \\
\hline Sacarose & + & + & - & - & - & - & - & - & - \\
\hline Melibiose & + & + & + & + & + & + & + & - & - \\
\hline Amigdalina & + & + & - & - & - & - & + & - & - \\
\hline Arabinose & + & + & - & - & - & - & + & + & - \\
\hline Citocromo oxidase & - & - & + & + & + & + & + & + & + \\
\hline EMB & + & + & + & + & + & + & + & - & + \\
\hline McConkey & + & + & - & - & - & - & - & - & - \\
\hline Cor da colônia em ágar nutriente & $\mathrm{B}$ & $\mathrm{B}$ & $\mathrm{B}$ & $\mathrm{B}$ & B & B & $\mathrm{B}$ & $\mathrm{B}$ & A \\
\hline
\end{tabular}


rizosfera de arroz (Shen et al., 1996). Embora outras enterobactérias, como as pertencentes ao gênero Klebsiella, sejam freqüentemente citadas entre as diazotróficas associadas às raízes ou à parte aérea de cana-de-açúcar (Li \& MacRae, 1992) e mandioca (Balota et al., 1999), elas não foram encontradas em amostras de coqueiro neste estudo.

Os resultados dos testes das galerias API 20-E indicaram que todas as bactérias antes denominadas pseudomonadas pertencem ao gênero Pseudomonas. Estes mesmos testes permitiram a identificação das espécies dos isolados 18 e 19, como Pseudomonas cepacia e Pseudomonas paucimobilis respectivamente. No entanto, a determinação das espécies dos outros isolados de pseudomonas não foi possível pelo sistema API 20-E. Os isolados 16 e 17 foram identificados, pelo sistema API 20-NE, como Pseudomonas stutzeri e apresentaram resultados positivos para a redução do nitrato, atividade de urease e citocromo-oxidase e utilização de glicose, manitol, maltose, gluconato, caprato, malato e citrato.

Não foi possível determinar as espécies dos isolados 14,15 e 20 , mesmo com este sistema para pseudomonados. As identificações dos isolados 18 e 19 como Pseudomonas cepacia e Pseudomonas paucimobilis no sistema API 20-E foram confirmadas no sistema API 20-NE.

Embora o Manual de bacteriologia determinativa de Bergey (Holt et al., 1994) inclua todas as espécies de pseudomonadas identificadas nesse estudo no gênero Pseudomonas, publicações anteriores a esta edição do referido Manual já consideravam algumas destas espécies como pertencentes a outros gêneros. A espécie Pseudomonas paucimobilis foi transferida para o gênero Sphingomonas (Yabuuchi et al., 1990) e Pseudomonas cepacia para o gênero Burkholderia (Yabuuchi et al., 1992). Pseudomonas stutzeri, no entanto, foi mantida como Pseudomonas.

Essas três espécies de pseudomonadas têm sido relatadas na literatura como dotadas de potencial diazotrófico. Isolados diazotróficos de Sphingomonas (Pseudomonas) paucimobilis foram encontrados na rizosfera de arroz (Engelhard et al.,
2000), milheto e sorgo (Hebbar et al., 1992). De acordo com Vermeiren et al. (1999), um isolado utilizado como inoculante para arroz, antes classificado como Alcaligenes faecalis A15, é, na realidade, uma estirpe de Pseudomonas stutzeri. Embora Burkholderia cepacia tenha sido isolada no presente estudo apenas de folhas de coqueiro, esta espécie foi anteriormente encontrada colonizando raízes de milho (Hernandez et al., 1995) e sorgo (Chiarini et al., 1998). Outras duas espécies de diazotróficas pertencentes ao gênero Burkholderia, B. vietnamensis e B. brasilensis têm sido encontradas em associação com raízes, caules e folhas de cereais, cana-de-açúcar, plantas produtoras de tubérculos, e palmeiras (Tran Van et al., 1994; Reis et al., 2000).

As quantidades de $\mathrm{N}$ fixado no meio semi-sólido variaram significativamente entre as estirpes (Tabela 3). De modo geral, observou-se que os valores obtidos nos frascos com inoculação de enterobactérias foram menores dos que nos frascos com inoculação de Pseudomonas spp. As estirpes 14 e 15 , identificadas como Pseudomonas sp., e isoladas a partir de folhas desinfectadas superficialmente foram as diazotróficas mais eficientes, de acordo com os testes realizados, fixando cerca de 116 a $126 \mu \mathrm{g}$ de $\mathrm{N}$ por frasco, após oito dias de incubação.

A baixa capacidade de fixação de $\mathrm{N}_{2}$ por estirpes de Enterobacter cloacae, comparativamente a outras diazotróficas isoladas da vegetação natural da região do Sinai, que incluem estirpes de Pseudomonas, foi relatada anteriormente por Sedik (1997).

Entre as estirpes isoladas neste estudo, as identificadas como 14 e 15 de Pseudomonas sp. parecem ser as de maior potencial de promoção do crescimento do coqueiro, pelo fato de serem endofiticas e apresentarem elevada capacidade de fixar $\mathrm{N}_{2}$, em comparação com outras diazotróficas isoladas desta cultura. Além disso, a filosfera de coqueiro tem sido sugerida como um habitat apropriado para o crescimento de diazotróficas capazes de utilizar as ceras das folhas desta planta como fonte de carbono. Entre as diazotróficas com esta capacidade, são relatadas duas espécies: Pseudomonas azotogensis e P. azotocolligans (Samanta et al., 1986). 
Tabela 3. Quantidade de N fixado biologicamente pelos isolados de bactérias diazotróficas inoculados em frascos contendo $5 \mathrm{~mL}$ de meio semi-sólido, após oito dias de incubação a $32^{\circ} \mathrm{C}$

\begin{tabular}{|c|c|c|c|c|c|}
\hline \multirow[t]{2}{*}{ Isolado } & \multirow[t]{2}{*}{ Identificação } & \multirow{2}{*}{$\begin{array}{l}\text { Meio utilizado } \\
\text { no isolamento }\end{array}$} & \multirow[t]{2}{*}{ Origem } & \multicolumn{2}{|c|}{$\mathrm{N}$ fixado biologicamente $(\mu \mathrm{g} /$ frasco $)$} \\
\hline & & & & $\operatorname{Variação~}^{(1)}$ & Média \\
\hline 1 & Enterobacter cloacae & $\mathrm{JNFb}$ & Raízes não desinfectadas & $15-23$ & 19 \\
\hline 2 & Enterobacter cloacae & $\mathrm{JNFb}$ & Raízes desinfectadas & $26-37$ & 29 \\
\hline 3 & Enterobacter cloacae & $\mathrm{JNF} b$ & Raízes desinfectadas & $14-25$ & 20 \\
\hline 4 & Enterobacter cloacae & $\mathrm{JNFb}$ & Folhas não desinfectadas & $16-23$ & 21 \\
\hline 5 & Enterobacter cloacae & $\mathrm{JNFb}$ & Folhas não desinfectadas & $12-38$ & 24 \\
\hline 6 & Enterobacter cloacae & $\mathrm{JNF} b$ & Folhas desinfectadas & $20-32$ & 23 \\
\hline 7 & Enterobacter cloacae & $\mathrm{JNF} b$ & Folhas não desinfectadas & $15-28$ & 18 \\
\hline 8 & Enterobacter cloacae & $\mathrm{JNF} b$ & Folhas não desinfectadas & $21-28$ & 23 \\
\hline 9 & Enterobacter cloacae & $\mathrm{JNF} b$ & Raízes desinfectadas & $13-29$ & 19 \\
\hline 10 & Enterobacter sp. & $\mathrm{JNF} b$ & Raízes desinfectadas & $21-30$ & 25 \\
\hline 11 & Enterobacter sp. & $\mathrm{JNF} b$ & Folhas não desinfectadas & $8-23$ & 16 \\
\hline 12 & Enterobacter sp. & $\mathrm{JNF} b$ & Raízes desinfectadas & $14-35$ & 28 \\
\hline 13 & Enterobacter sp. & $\mathrm{JNFb}$ & Raízes desinfectadas & $12-22$ & 18 \\
\hline 14 & Pseudomonas sp. & $\mathrm{NFb}$ & Folhas desinfectadas & $65-173$ & 127 \\
\hline 15 & Pseudomonas sp. & $\mathrm{NFb}$ & Folhas desinfectadas & $75-149$ & 116 \\
\hline 16 & Pseudomonas stutzeri & $\mathrm{NFb}$ & Folhas não desinfectadas & $32-95$ & 65 \\
\hline 17 & Pseudomonas stutzeri & $\mathrm{NFb}$ & Folhas não desinfectadas & $63-110$ & 93 \\
\hline 18 & Burkholderia cepacia & $\mathrm{JNF} b$ & Folhas não desinfectadas & $46-63$ & 56 \\
\hline 19 & Sphingomonas paucimobilis & $\mathrm{NFb}$ & Raízes não desinfectadas & $4-11$ & 8 \\
\hline 20 & Pseudomonas sp. & $\mathrm{NFb}$ & Folhas não desinfectadas & $82-142$ & 113 \\
\hline
\end{tabular}




\section{Conclusões}

1. A superfície e o interior das folhas e raízes dos coqueiros híbridos PB121 são colonizadas por bactérias diazotróficas dos grupos das enterobacteriáceas e das bactérias com características similares às do gênero Pseudomonas.

2. Bactérias pseudomonadas encontradas nas folhas são predominantemente endofíticas, e as encontradas nas raízes distribuem-se, em proporções semelhantes, entre a superfície e o interior desse órgão.

3. Enterobactérias diazotróficas colonizam preferencialmente o interior das folhas e a superfície das raízes do coqueiro.

4. Das bactérias isoladas de coqueiro, as pseudomonadas apresentam maior potencial de fixação de nitrogênio do que as enterobactérias.

\section{Agradecimentos}

Ao assistente de pesquisa Jadson Alves Nascimento, e às estagiárias Hosanaide Baptista dos Santos e Graziela Baptista Ferreira, pela contribuição na condução dos experimentos em laboratório.

\section{Referências}

BALDANI, V. L. D.; BALDANI, J. I.; OLIVARES, F. L.; DÖBEREINER, J. Identification and ecology of Herbaspirillum seropedicae and the closely related Pseudomonas rubrisubalbicans. Symbiosis, Rehovot, v. 13 , p. $65-73,1992$.

BALOTA, E. L.; LOPES, E. S.; HUNGRIA, M.; DÖBEREINER, J. Inoculação de bactérias diazotróficas e fungos micorrízico-arbusculares na cultura da mandioca. Pesquisa Agropecuária Brasileira, Brasília, v. 32, n. 6 , p. 627-639, jun. 1997

BALOTA, E. L.; LOPES, E. S.; HUNGRIA, M.; DÖBEREINER, J. Ocorrência de bactérias diazotróficas e fungos micorrízico-arbusculares na cultura da mandioca. Pesquisa Agropecuária Brasileira, Brasília, v. 34, n. 7, p. 1265-1276, jul. 1999

CHIARINI, L.; BEVIVINO, A.; TABACCHIONI, S.; DALMASTRI, C. Inoculation of Burkholderia cepacia, Pseudomonas fluorescens and Enterobacter sp. on
Sorghum bicolor: root colonization and plant growth promotion of dual strain inocula. Soil Biology \& Biochemistry, Oxford, v. 30, p. 81-87, 1998.

DÖBEREINER, J.; BALDANI, V. L. D.; BALDANI, J. I. Como isolar e identificar bactérias diazotróficas de plantas não-leguminosas. Brasília: Embrapa-SPI, 1995. 60 p

EMBRAPA. Centro Nacional de Pesquisa de Solos (Rio de Janeiro, RJ). Manual de métodos de análises de solo Rio de Janeiro, 1997. 212 p. (Documentos, 1).

ENGELHARD, M.; HUREK, T.; REINHOLD-HUREK, B. Preferential occurrence of diazotrophic endophytes, Azoarcus spp., in wild rice species and land races of Oryza sativa in comparison with modern races. Environmental Microbiology, Oxford, v. 2, p. 131-141, 2000.

HEBBAR, K. P.; GUENIOT, B.; HEYRAUD,A.; COLINMOREL, P.; HEULIN, T.; BALANDREAU, J.; RINAUDO, M. Characterization of exopolysaccharides produced by rhizobacteria. Applied Microbiology and Biotechnology, Berlin, v. 38, p. 248-253, 1992.

HERNANDEZ, A. N.; HERNANDEZ, A.; HEVDRICH, M. Selección de rizobacterias asociadas al cultivo del maíz. Cultivos Tropicales, Havana, v. 16, p. 5-8, 1995

HINTON, D. M.; BACON, C. W. Enterobacter cloacae is an endophytic symbiont of corn. Mycopathologia, Dordrecht, v. 129, p. 117-125, 1995

HOLT, J. G.; KRIEG, N. R.; SNEATH, P. H. A.; STALEY, J. T.; WILLIAMS, S. T. Bergey's manual of determinative bacteriology. 9. ed. Baltimore: Williams \& Wilkins, 1994. $787 \mathrm{p}$.

JACKSON, M. L. Soil chemical analysis. New Jersey: Prentice Hall, 1958. 489 p

KLEEBERGER,A.; CASTROPH, H.; KLINGMÜLLER, $\mathrm{W}$. The rhizosphere microflora of wheat and barley with special reference to gram negative bacteria. Archives of Microbiology, Berlin, v. 136, p. 306-311, 1983.

LI, R. P.; MacRAE, I. C. Isolation and identification of $\mathrm{N}_{2}$-fixing enterobacteria associated with sugarcane in tropical Australia. Journal of General and Applied Microbiology, Tokyo, v. 38, p. 523-531, 1992.

MITCHELL, H. T. Microdetermination of nitrogen in plant tissues. Journal of the Association of Official Agricultural Chemists, Washington, v. 55, p. 1-3, 1972.

NAIR, S. K.; SUBBA RAO, N. S. Distribution and activity of phosphate-solubilizing micro-organisms in the rhizosphere of coconut and cacao under mixed cropping. Journal of Plantation Crops, Kasaragod, v. 5, p. 67-70, 1977. 
REIS, V. M.; BALDANI, J. I.; BALDANI, V. L. D.; DÖBEREINER, J. Biological dinitrogen fixation in gramineae and palm tree. Critical Reviews in Plant Sciences, Boca Raton, v. 19, p. 227-247, 2000.

SALAMONE, I. E. G. de; DÖBEREINER, J.; URQUIAGA, S.; BODDEY, R. M. Biological nitrogen fixation in Azospirillum strain-maize genotype associations as evaluated by the ${ }^{15} \mathrm{~N}$ isotope dilution technique. Biology and Fertility of Soils, Berlin, v. 23, p. 249-256, 1996.

SAMANTA, R.; DUTTA,A. K.; SEM, S. P. The utilization of leaf wax by $\mathrm{N}$-fixing microorganisms on the leaf surface Journal of Agricultural Science, Cambridge, Inglaterra, v. 107 , p. $681-685,1986$

SEDIK, M. Z. Biodiversity of diazotrophs associated with natural vegetation of North Sinai. Faculty of Agriculture of the University of Cairo Bulletin, Cairo, v. 48, p. 143 158,1997

SHEN, B. F.; ZHU, H. R.; LI, J. Response of rice to inoculation with genetic engineered strains of associative diazotrophics. Chinese Rice Research Newsletter, Beijing, v. 4, p. 4-5, 1996.

SUBBA RAO, N. S. Nitrogen-fixing bacteria associated with plantation and orchard plants. Canadian Journal of Microbiology, Ottawa, v. 29, p. 863-866, 1983.

THOMAS, G. V.; IYER, R.; BOPAIAH, B. M. Beneficial microbes in the nutrition of coconut. Journal of Plantation Crops, Kasaragod, v. 19, p. 127-138, 1991.
TRAN VAN, V.; MAVINGUI, P.; BERGE, O.; BALANDREAU, J.; HEULIN, T. Promotion de croissance du riz inocule par une bacterie fixatrice d'azote, Burkholderia vietnamiensis, isoleé d'une sol sulfate acide du Viet-nam. Agronomie, Paris, v. 14, p. 697-707, 1994.

VERMEIREN, H.; WILLEMS,A.; SCHOOFS, G.; MOT, R. de; KEIJERS, V.; HAI, W.; VANDERLEYDEN, J. The rice inoculant strain Alcaligenes faecalis $\mathrm{A} 15$ is a nitrogenfixing Pseudomonas stutzeri. Systematic and Applied Microbiology, Jena, v. 22, p. 215-224, 1999.

WATANABE, I.; SO, R.; LADHA, J. K.; KATAYAMAFUJIMURA, Y.; HURAISHI, H. A new nitrogen-fixing species of Pseudomonas diazotrophicus sp. nov. isolated from the root of wetland rice. Canadian Journal of Microbiology, Ottawa, v. 33, p. 670-678, 1987.

YABUUCHI, E.; KOSAKO, Y.; OYAIZU, H.; YANO, I.; HOTTA, H.; HASHIMOTO, Y.; EZAKI, T.; ARAKAWA, M. Proposal of Burkholderia gen. nov. and transfer of seven species of the genus Pseudomonas homology group II to the new genus, with the type species Burkholderia cepacia (Palleroni and Holmes 1981) comb. nov. Microbiology and Immunology, Tokyo, v. 36, p. 1251-1275, 1992.

YABUUCHI, E.; YANO, H.; OYAIZU, Y.; HASHIMOTO, T.; ZAKI, E.; YAMAMOTO, H. Proposals of Sphingomonas paucimobilis gen. nov. and comb. nov., Sphingomonas parapaucimobilis sp. nov. Sphingomonas yanoikuyae sp. nov. , Sphingomonas adhaesiva sp. nov. Sphingomonas capsulata comb. nov. and two genospecies of the genus Sphingomonas. Microbiology and Immunology, Tokyo, v. 34, p. 99-119, 1990 